\title{
ORIGEM, SUCESSÃO E ESTRUTURA DE UMA FLORESTA DE GALERIA PERIODICAMENTE ALAGADA EM VIÇOSA-MG ${ }^{1}$
}

\author{
João Augusto Alves Meira Neto², Maílson Monteiro do Rêgo ${ }^{3}$, Danilo José da Silva Coelho ${ }^{4}$ \\ Francisco Glicério Ribeiro ${ }^{5}$
}

\begin{abstract}
RESUMO - O estudo das estruturas fitossociológicas e de tamanhos em fragmentos florestais secundários permite inferências a respeito da composição e das estruturas originais do início da sucessão secundária. Em se tratando de matas de galeria ou ciliares, a importância desses estudos aumenta com a crescente pressão causada por impactos em cursos d'água e suas margens, especialmente as construções de barragens para hidrelétricas. Com este trabalho objetivou-se descrever a estrutura de uma mata de galeria secundária e, a partir desta, identificar uma população de espécie arbórea que participou do início do processo sucessional nessa floresta. Em seguida, com esses dados, objetivou-se estudar a estrutura genética e levantar dados sobre a biologia dessa espécie, que provavelmente iniciou o processo sucessional. Foi realizado um censo de todas as árvores que apresentassem circunferência do caule a 1,3 m do solo maior ou igual a $10 \mathrm{~cm}$. Das 48 espécies de árvores incluídas, 87,5\% são endozoocóricas e 12,5 anemocóricas. Das anemocóricas, as com menores diásporos apresentaram maior densidade nessa floresta, que está isolada das outras por pastagens. A mata de galeria em questão apresentou como espécies mais importantes (VI) ovata, Erythrina falcata e Euterpe edulis. Espécies de Ficus do subgênero Urostigma apresentaram grande biomassa, apesar da baixa densidade. Erythrina falcata foi considerada uma das espécies de maior importância, provavelmente associada às espécies de Ficus, no início da sucessão secundária, pela estrutura de diâmetros de caule por ela apresentada. Em Erythrina falcata foram analisados os sistemas isoenzimáticos de Isocitrato Desidrogenase, Peroxidase, Fosfogluco Mutase e Xiquimato Desidrogenase por meio de zimogramas. A população dos 27 indivíduos de Erythrina falcata mostrou-se em equilíbrio de Hardy-Weinberg e com relativa alta diversidade alélica. A população de Erythrina falcata mostrou possuir condições biológicas e ecológicas para iniciar a sucessão secundária. A alta diversidade genética da população de Erythrina falcata pode ter sido um dos fatores determinantes do sucesso de colonização da área. A associação de Erythrina falcata com figueiras pode ter sido determinante no sucesso desse processo em seu início, e a associação inicial deve ter funcionado como sistema de baixa diversidade de espécies, comparável a outras florestas alagadas do Sudeste brasileiro.
\end{abstract}

Palavras-chave: Fitossociologia, dispersão, Erythrina falcata Behnt. e estrutura genética de população.

\section{ORIGIN, SUCCESSION AND STRUCTURE OF A PERIODICALLY FLOODED GALLERY FOREST IN VIÇOSA, MINAS GERAIS, BRAZIL}

\begin{abstract}
The study of the phytosociological structures and sizes in secondary forest fragments allows to make inferences on the original composition and structures at the beginning of the secondary succession. The importance of gallery or riparian forest studies increases with the increasing concerns on the impacts caused by water courses and their borders, specially the building of power plant dams. The objectives of this work were to describe the structure of a secondary gallery forest to identify an arboreous species population which participated at the beginning of the successional process in this forest and based on these data, to study the genetic structure and to assess the biology of the species which probably started the successional process. A survey of all the trees
\end{abstract}

1 Recebido para publicação em 7.8.2001.

Aceito para publicação em 9.9.2003.

2 Dep. de Biologia Vegetal da Universidade Federal de Viçosa - UFV, 36570-000 Viçosa-MG, <j.meira@ ufv.br>. ${ }^{3}$ Dep. de Fitotecnia da Universidade Federal de Roraima, 69311-270, <mmrego@bol.com.br>. ${ }^{4}$ Centro de Pesquisa em Manejo e Recuperação de Mata Atlântica, IEF-MG, Vila Gianetti, Casa 51, Campus Universitário - UFV; ${ }^{5}$ Laboratório de Melhoramento de Hortaliças - Dep. de Fitotecnia da UFV. 
with a 1,3 $\mathrm{m}$ stem circumference from the ground greater than or equal to $10 \mathrm{~cm}$ was carried out. Out of the 48 tree species already included, $87.5 \%$ are endozoochoric and $12.5 \%$ are anemochoric. Out of the latter those with the smallest propagules presented greater density in this forest, which is isolated from others by pastures. The most important species (VI) presented by this gallery forest were: Talauma ovata, Erythrina falcata and Euterpe edulis. Ficus species from the subgenus Urostigma presented a great biomass in spite of its low density. Erythrina falcata was considered one of the species of greater importance, probably associated to the Ficus species at the beginning of the secondary succession, due to the structure of the stem diameters presented. In Erythrina falcata, the isoenzymatic systems of Isocitrate Dehydrogenase, Peroxidase, Phosphoglyco Mutase and Xiquimate Dehydrogenase were analyzed by means of zimograms. The population of 27 individuals of Erythrina falcata was found in Hardy-Weinberg balance, presenting a relatively high allelic diversity. The population of Erythrina falcata was found to be under biological and ecological conditions to start the secondary succession. The high genetic diversity of the Erythrina falcata population could be one of the determinant factors for the success of the colonization of the area. The association of Erythrina falcata with trees of the Ficus genus could have been determinant for the successful beginning of this process of colonization, and the initial association may have functioned as a low diversity system of species, comparable to other flooded forests of Southeastern Brazil.

Key words: Phytosociology, dispersal, Erythrina falcata Behnt. and population genetic structure.

\section{INTRODUÇÃO}

No centro-sul brasileiro a alteração da vegetação natural associada a cursos d'água tem se acelerado em função da demanda crescente de energia, em um país que fundamenta sua produção de eletricidade nas usinas hidrelétricas (Meira Neto et al., 1997).

$\mathrm{O}$ grande potencial hidrelétrico ainda inexplorado na Zona da Mata de Minas Gerais evidencia a grande preocupação ambiental com a conservação, a proteção e a recomposição das matas de galeria. Este tipo florestal ocorre apenas em áreas de influência direta da umidade proporcionada pelos rios, pelas represas e por outros corpos d'água.

O impacto causado pelo enchimento de reservatórios suprime a vegetação ribeirinha original pela alteração drástica do ambiente. Invariavelmente, a elevação do nível da lâmina d'água de um reservatório resulta em um perímetro com margens constituídas por antigos campos de cultivo e pastagens, desprovidos de vegetação natural e altamente sucetíveis à erosão, o que pode resultar em maior degradação do ambiente e no assoreamento do corpo d'água.

A reconstituição da vegetação florestal marginal de corpos d'água assume papel importante na viabilização de projetos hidrelétricos nesse momento em que a sustentabilidade das atividades é o tema central dos futuros modelos produtivos. Essa atividade não é comum, nem tampouco de sucesso garantido. Além dos problemas técnicos relacionados com a implantação de uma floresta de galeria, há carência de estudos estruturais desse tipo de vegetação que levem em consideração o processo sucessional. As publicações sobre florística e fotossociologia de vegetação ripária são de florestas de galeria em processo avançado de sucessão, que não fornecem estruturas de tamanho, nem histórico de perturbação (Schiavini, 1992; Oliveira-Filho et al., 1994a, b; SilvaJúnior et al., 1996; Meira-Neto et al., 1997, 1998; Sevilha, 1999), essenciais ao entendimento do processo sucessional.

Para obtenção de um modelo estrutural utilizável na recomposição de matas de galeria é necessário um estudo fitossociológico nas florestas de mesma tipologia que sejam próximas geograficamente ao trecho a ser recomposto (Meira-Neto et al., 1997). Modelos e estratégias de restauração das matas de galeria se fundamentam no entendimento de suas estruturas e de seu funcionamento como sistemas em equilíbrio dinâmico (Kageyama, 1986).

Em florestas secundárias, estudos da estrutura de tamanho estabelecida pelas distribuições de freqüências diamétricas das populações de cada espécie possibilitam inferir sobre quais populações são as mais antigas, quais vieram na seqüência, e assim por diante. No caso da mata de galeria periodicamente alagada da fazenda Bom Sucesso, um pequeno fragmento florestal que se originou 
espontaneamente em uma nascente rodeada por pastagem, é fundamental entender sua estrutura para determinação de seu histórico, para compreensão do desenvolvimento e funcionamento desse sistema nas condições em que surgiu: em uma pastagem alagada periodicamente, condição das mais comuns nas margens dos reservatórios de hidrelétricas.

Após identificar qual ou quais populações provavelmente iniciaram a sucessão, somado às informações sobre a biologia dessas espécies colonizadoras, podem ser executados estudos genéticos com marcadores enzimáticos para o entendimento dos processos biológicos envolvidos na origem dessa floresta.

Os objetivos deste trabalho foram:

A - Descrever a estrutura fitossociológica e diamétrica da mata de galeria periodicamente alagada da fazenda Bom Sucesso e, a partir desta, identificar uma população de espécie arbórea que participou do início do processo sucessional nessa floresta.

B - Estudar a estrutura genética e levantar dados sobre a biologia dessa espécie, que provavelmente iniciou o processo sucessional.

\section{MATERIAL E MÉTODOS}

\section{1. Área de Estudos}

\subsubsection{O Município de Viçosa}

O município de Viçosa situa-se perifericamente no norte da Zona da Mata de Minas Gerais, entrecortado por rios e córregos tributários do rio Doce (MariscalFlores, 1993; Valverde, 1958). O centro da cidade de Viçosa tem altitude de $650 \mathrm{~m}$, mas são encontradas altitudes maiores que $800 \mathrm{~m}$ nos topos dos muitos morros do município (COMISSÃO GEOGRÁFICA E GEOLÓGICA DE MINAS GERAIS, 1930).

O relevo varia de fortemente ondulado a montanhoso. Os solos do município apresentam a predominância de duas classes: nos topos de morros e encostas predomina o Latossolo Vermelho-Amarelo Distrófico, enquanto nos terraços a predominância é de Argissolo Vermelho-Amarelo (Rezende, 1971; Correa, 1983; Embrapa, 1999). A mata de galeria periodicamente alagada está em um terraço (Figura 1).

O clima é tropical de altitude, com verões chuvosos e invernos frios e secos, do tipo Cwb pelo sistema de
Köppen (Golfari, 1975). A precipitação média anual é de 1.221,4 mm (DEPARTAMENTO NACIONAL DE METEOROLOGIA, 1992).

O balanço hídrico, segundo Thornthwaite \& Mather (1955), citados por Golfari (1975), mostra a existência de um período com excedente hídrico a partir de novembro, que perdura até abril. De abril a setembro a precipitação cai abaixo da evapotranspiração potencial, causando deficiência hídrica e retirada de água do solo. De setembro a novembro há reposição de água no solo, com o aumento da precipitação. Assim, ficam caracterizadas uma estação chuvosa de setembro a abril e uma estação seca de abril a setembro.

A mata de galeria periodicamente alagada, doravante denominada apenas de mata alagada (Figura 1), é uma floresta estacional semidecidual aluvial (Veloso et al., 1991) de 0,175 ha que, segundo dados levantados com moradores locais, resultou de um processo de sucessão ecológica secundária a partir de uma área de pastagem em torno de uma nascente. Presume-se que o pisoteio do gado ao redor dessa nascente tenha desestruturado o solo, tornando-o lamacento, o que somado à deposição de sedimentos carreados do entorno transformou o local num "atoleiro". Assim, o gado ficou impedido de acessar a porção central desse trecho, o que permitiu o estabelecimento de plantas adaptadas às condições iniciais desse ambiente.

\subsection{Estrutura Fitossociológica}

Para o estudo fitossociológico foi realizado um censo em que foram incluídas todas as plantas lenhosas eretas que possuíam diâmetro do caule à altura do peito (DAP) maior ou igual a $3,18 \mathrm{~cm}$. Os indivíduos amostrados foram coletados, indentificados e, quando em fenofase reprodutiva, incorporados à coleção do Herbário VIC, do Departamento de Biologia Vegetal da Universidade Federal de Viçosa.

A lista florística com os respectivos autores das espécies estão em SILVA (2003).

Os parâmetros fitossociológicos calculados foram a densidade e dominância absolutas e, a partir de seus valores relativos, o valor de cobertura (VC), segundo as fórmulas costumeiramente utilizadas em estudos fitossociológicos no Brasil (Mueller-Dombois \& Ellenberg, 1974; Martins, 1991).

Para calcular os referidos parâmetros foi utilizado o software Fitopac 1 (Shepherd, 1994).

R. Árvore, Viçosa-MG, v.27, n.4, p.561-574, 2003 


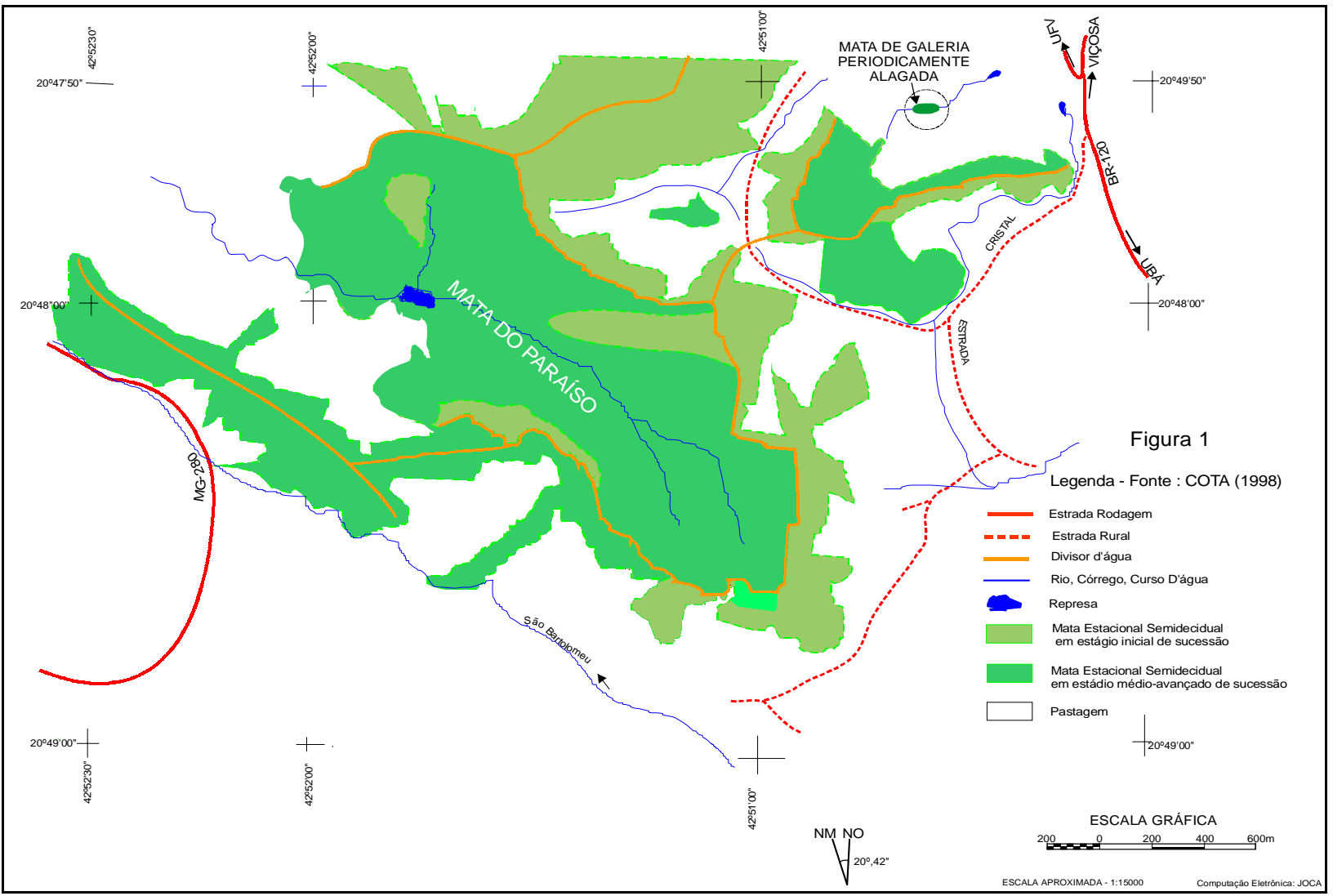

Figura 1 - Localização da mata de galeria periodicamente alagada, a mata alagada.

Figure 1 - Location periodically flooded gallery forest.

\subsection{Estrutura Diamétrica}

A distribuição de frequiência diamétrica foi feita mediante o cômputo dos indivíduos amostrados de cada uma das espécies dentro da classe diamétrica a que pertencem (Harper, 1977). As classes de diâmetro foram estabelecidas com amplitude de $10 \mathrm{~cm}$, a partir do diâmetro mínimo de $3,18 \mathrm{~cm}$.

Para obtenção das tabelas de distribuição diamétrica foi utilizado o software Diamfito (Mota, 1995).

Para análise de correlação entre o número de indivíduos na vegetação e o tamanho dos diásporos foi utilizada a correlação por postos de Spearman $\left(r_{s}\right)$, utilizando-se a seguinte fórmula (Spiegel, 1974):

$$
r_{s}=1-\left(6 \sum_{i=1}^{N} d i^{2} / N^{3}-N\right)
$$

em que $N$ corresponde ao número de postos.

R. Árvore, Viçosa-MG, v.27, n.4, p.561-574, 2003

\subsection{Isoenzimas}

\subsubsection{Análise Eletroforética}

O estudo da variabilidade genética do sistema de cruzamento baseou-se no polimorfismo isoenzimático. Foram testados oito sistemas enzimáticos: Esterase (Est) Fosfogluco isomerase (Pgi), Fosfoglucomutase (Pgm), Glutamato oxaloacetato desidrogenase (Got), Isocitrato desidrogenase (Idh), Malato desidrogenase $(M d h)$, Peroxidase $(\operatorname{Pr} x)$ e Xiquimato dsidrogenase $(S k d)$.

\subsubsection{Material Vegetal}

Amostras de folhas jovens (brotos) de Erythrina falcata foram coletadas no campo, acondicionadas em caixa de isopor com gelo e levadas ao Laboratório de Melhoramento de Hortaliças do Departamento de Fitotecnia da Universidade Federal de Viçosa, onde foram 
feitas as análises eletroforéticas. Esta espécie foi escolhida por possuir população numerosa e por sua estrutura diamétrica mostrar que predominam indivíduos de diâmetros intermediários a maiores. Este fato mostra que Erythrina falcata é espécie colonizadora e chegou à referida comunidade em estádios sucessionais anteriores à atual etapa seral.

\subsubsection{Tampão de Extração}

Cada amostra de tecido foi macerada em $1 \mathrm{ml} \mathrm{de}$ solução de extratora número 1, conforme Alfenas et al. (1991). O extrato foi absorvido em retângulos de papel cromatográfico Whatman 3MM.

\subsubsection{Tampões dos Géis e Eletrodos}

O gel utilizado foi o de amido hidrolisado (Sigma gel), a $12 \%$. Os sistemas-tampão utilizados no preparo dos géis e nos eletrodos foram o Soltis et al. (1983) e o Shaw \& Prasad (1970).

\subsubsection{Condições da Corrida Eletroforética}

A corrida eletroforética ocorreu a $4{ }^{\circ} \mathrm{C}$, sob voltagem constante de $200 \mathrm{~V}$, até que a frente de azul-de-bromofenol atingisse $8 \mathrm{~cm}$ a partir da origem.

\subsubsection{Coloração e Interpretação dos Zimogramas}

Cortou-se o gel longitudinalmente em quatro fatias de $2 \mathrm{~mm}$ de espessura, as quais receberam a solução corante específica para cada enzima, conforme Alfenas et al. (1991).

Após a revelação, o corante foi descartado e o gel foi fixado em glicerina a $10 \%$, por cerca de 12 horas, a $4{ }^{\circ} \mathrm{C}$. Após este período a glicerina foi substituída por uma solução a $65 \%$ de álcool etílico, $30 \%$ de água e $5 \%$ de glicerina, durante 5 minutos. A secagem do gel foi realizada pelo método do bastidor, descrito por Alfenas et al. (1991). A leitura das bandas nos géis foi feita sobre a superfície de um diafanoscópio.

\subsubsection{Variabilidade Genética da População de Erythrina falcata}

Os estimadores da variabilidade genética nas populações foram as frequiências alélicas, o número médio de alelos por loco, a porcentagem de loci polimórficos e a heterozigosidade média observada. $\mathrm{O}$ desvio do equilíbrio foi avaliado pelo teste quiquadrado e quantificado pelo índice de fixação de Wright $(\hat{\mathrm{I}}=(\mathrm{He}-\mathrm{Ho}) / \mathrm{He}$, em que He é a freqüência de heterozigotos no equilíbrio de Hardy-Weinberg; e Ho é a freqüência observada de heterozigotos na população.

\subsubsection{Sistema de Cruzamento}

Para obtenção da estimativa da taxa de cruzamento utilizou-se a análise de variância, de acordo com Muniz et al. (1996).

\section{RESULTADOS E DISCUSSÃO}

\subsection{Estrutura Fitossociológica}

Foram incluídos 377 indivíduos arbóreos de 48 espécies, pertencentes a 22 famílias de angiospermas e a uma família de pteridófitas (Quadro 1). As cinco populações mais representativas pelo VC (valor de cobertura) foram, em ordem decrescente, as de Talauma ovata, Erythrina falcata, Ficus guaranitica, Euterpe edulis e Schinus terebinthifolius; pela biomassa (dominâncias absolutas) foram as de Erythrina falcata, Ficus guaranitica, Talauma ovata, Euterpe edulis e Ficus trigona; e pelo número de indivíduos (densidades absolutas) foram as de Talauma ovata, Euterpe edulis, Erythrina falcata, Schinus terebinthifolius e Casearia sylvestris.

Quando foram analisadas apenas as espécies de angiospermas representadas, constatou-se que seis (12,5\%) são anemocóricas e as demais são endozoocóricas $(87,5 \%)$, o que revela um padrão diferente daqueles descritos para outras florestas estacionais semideciduais do Sudeste brasileiro por Mathes (1980) e Morellato \& Leitão-Filho (1992), em que de 22 a $26 \%$ das espécies são anemocóricas, 69 a $70 \%$ são zoocóricas e 5 a $8 \%$ são autocóricas. Entretanto, outras florestas tropicais podem apresentar mais de 90\% de espécies zoocóricas (Gentry, 1983). Embora esteja dentro da variação de proporções dos tipos de dispersão em florestas tropicais como um todo, para uma floresta estacional semidecidual os $87 \%$ de espécies zoocóricas e a ausência de espécies autocóricas demonstram um padrão incomum encontrado na mata alagada, o que pode ser explicado pelo histórico de colonização do local.

$$
\text { R. Árvore, Viçosa-MG, v.27, n.4, p.561-574, } 2003
$$


Quadro 1 - Parâmetros fitossociológicos: DA - densidade absoluta, DoA - dominância absoluta e VC - valor de cobertura

Table 1 - Phytosociological parameters: DA - absolute density, DoA-absolute dominance, $V C$ - cover value

\begin{tabular}{|c|c|c|c|}
\hline Espécie & $\begin{array}{c}\text { DA } \\
\text { (ind/ha) }\end{array}$ & $\begin{array}{c}\text { DoA } \\
\left(\mathrm{m}^{2} / \mathrm{ha}\right)\end{array}$ & $\mathrm{VC}$ \\
\hline Talauma ovata & 588,6 & 13,0116 & 43,49 \\
\hline Euterpe edulis & 194,3 & 3,2118 & 13,01 \\
\hline Erythrina falcata * & 154,3 & 23,3931 & 36,23 \\
\hline Schinus terebinthifolius & 148,6 & l & 8,37 \\
\hline Casearia sylvestris & 114,3 & 2,2291 & 8,07 \\
\hline Guarea kunthiana & 108,6 & - & $\begin{array}{l}5,86 \\
5,26\end{array}$ \\
\hline Mortas & 68,6 & 1,5677 & 5,13 \\
\hline Cestrum coriaceum & 51,4 & 0,0820 & 2,49 \\
\hline Ficus trigona & 51,4 & 3,0447 & 6,17 \\
\hline Cyathea delgadii ** & 45,7 & 0,2543 & 2,44 \\
\hline Endlicheria paniculata & 40,0 & 0,6258 & 2,63 \\
\hline Ficus citrifolia & 40,0 & 0,9810 & 3,08 \\
\hline Rollinia laurifolia & 40,0 & 0,6700 & 2,69 \\
\hline Sorocea bonplandii & 34,3 & 0,1948 & 1,83 \\
\hline Piper sp. & 34,3 & 0,0667 & 1, \\
\hline Cecropia glaziovi & 28,6 & 1,0510 & 2,63 \\
\hline Maclura tinctoria & 28,6 & ( & 1,53 \\
\hline Tibouchina granulosa * & 28,6 & 0,5844 & 2,05 \\
\hline Mollinedia floribunda & 22,9 & 0,1941 & 1,30 \\
\hline Piper lhotzkyanum & 22,9 & 0,0397 & 1,11 \\
\hline Sapium biglandulosum & 22,9 & n & 2,05 \\
\hline Nectandra oppositifolia & 22,9 & 0,1307 & $\begin{array}{l}1,22 \\
1,3\end{array}$ \\
\hline Protium warmingianum & 22,9 & 0,1280 & 1,22 \\
\hline Ficus luschnathiana & 17,1 & 2,3729 & 3,74 \\
\hline Ficus guaranitica & 17, & 19,7659 & 25,35 \\
\hline Luehea grandiflora* & 17,1 & 0,1820 & $\begin{array}{l}1,02 \\
.+1,0\end{array}$ \\
\hline Syagrus romanzoffiana & 17,1 & (n) & $\begin{array}{l}1,69 \\
1,3\end{array}$ \\
\hline Alchornea iricurana & 11,4 & "0,1983 & 0,78 \\
\hline Trichilia lepidota & 11,4 & 0,0483 & 0,59 \\
\hline Xylopia sericea & 11,4 & (0,4021 & $\begin{array}{ll}1,03 \\
1, n, m\end{array}$ \\
\hline Alsophila sternbergii ** & 11,4 & (2) & 0,72 \\
\hline Solanum cernuum & 11,4 & 0,0591 & 0,60 \\
\hline Copaifera langsdorffii & 11,4 & 0,0266 & 0,56 \\
\hline Alophyllus petiolatus & (11,4 & (n) & 0,57 \\
\hline Piper aduncum & (11,4, & n & 0,55 \\
\hline Myrcia fallax & 5,7 & 0,0356 & 0,31 \\
\hline Swartzia myrtifolia & 5,7 & 0,0077 & 0,27 \\
\hline Vernonia rubriramea * & 5,7 & no, & 0,28 \\
\hline Machaerium nictitans * & 5,7 & 0,3209 & 0,66 \\
\hline Plathymenia foliolosa * & 5,7 & 0,8164 & 1,28 \\
\hline Inga laurina & 5,7 & 0,3362 & 0,68 \\
\hline Trichilia pallida & 5,7 & 0,0262 & 0,30 \\
\hline Trichilia emarginata & 5,7 & 0,0055 & 0,27 \\
\hline Andira fraxinifolia & 5,7 & 0,0356 & 0,31 \\
\hline Matayba elaeagnoides & 5,7 & 0,0247 & 0,30 \\
\hline Cabralea canjerana & 5,7 & 0,0220 & 0,29 \\
\hline Randia armata & 5,7 & 0,0200 & 0,29 \\
\hline Myrcia eriopus & 5,7 & 0,0102 & 0,28 \\
\hline Hyeronima alchorneoides & 5,7 & 0,5704 & 0,98 \\
\hline
\end{tabular}

* Espécies anemocóricas e ** plantas com esporos dispersos pelo vento.
Das populações de espécies anemocóricas, apenas Erythrina falcata tem importância destacada nessa floresta, sendo a principal detentora de biomassa e a terceira em número de indivíduos. Em um pequeno fragmento originado de um pasto degradado e isolado por pastagens, é esperado que a anemocoria tenha contribuído pouco com a chuva de diásporos que possibilitou a recolonização daquela área. Ortiz-Pullido et al. (1999) mostraram que a grande maioria das sementes que chegam em pastagens por ornitocoria é oriunda de outros locais. A presença de grandes fragmentos florestais às distâncias de centenas de metros a poucos quilômetros (Figura 1) faz com que a chuva de diásporos por endozoocoria seja mais efetiva que a chuva de diásporos por anemocoria, especialmente se for considerada a ação de poleiros criados pelas plantas colonizadoras.

\subsection{Estrutura Diamétrica}

Apenas cinco espécies apresentaram árvores com mais de $43 \mathrm{~cm}$ de diâmetro na mata alagada: Talauma ovata, Ficus trigona, Ficus luschnatiana, Ficus guaranitica e Erythrina falcata. As espécies Talauma ovata e Ficus trigona mostram suas populações com curvas tendendo a "J-invertido" (Meyer, 1952), demonstrando recrutamento de indivíduos jovens no atual estádio de desenvolvimento do fragmento. Ficus guranitica e Ficus luschnatiana, com poucos indivíduos (três em cada população), não têm populações estabelecidas. Ficus luschnatiana parece estar se estabelecendo vagarosamente, enquanto Ficus guaranitica dá mostras de estar saindo da comunidade (Quadro 2).

A estrutura de tamanhos da população de Erythrina falcata mostra que esta é antiga no fragmento, é decrescente em densidade de indivíduos nas menores classes de diâmetro e que, muito provavelmente, participou do estádio inicial da sucessão ecológica que resultou no atual fragmento, por possuir a maior densidade de indivíduos com mais de $43 \mathrm{~cm}$ de diâmetro de caule a $1,3 \mathrm{~m}$ de altura a partir do solo. Se esta população foi uma das colonizadoras da área, surgiu a partir de sementes que chegaram ao local por chuva de diásporos. Nessa espécie, reconhecidamente anemocórica, é possível ocorrer endozoocoria eventual, pois as sementes mimetizam besouros ou sementes com arilóides por possuírem manchas alaranjadas no tegumento escuro da semente (Krukoff, 1939), podendo ser ingeridas por pássaros, o que aumenta a probabilidade de sua chegada ao local em questão. 
Quadro 2 - Distribuições de freqüência de indivíduos por classes de diâmetros do caule com $10 \mathrm{~cm}$ de amplitude Table 2 - Individual frequency distribution by $10 \mathrm{~cm}$ range classes of stem diameters

\begin{tabular}{|c|c|c|c|c|c|c|c|c|c|}
\hline Espécies/classe $(\mathrm{cm})$ & $3-13$ & $13-23$ & $23-33$ & $33-43$ & $43-53$ & $53-63$ & $63-73$ & $>73$ & Total \\
\hline Talauma ovata & 76 & 16 & 1 & 6 & 3 & 1 & & & 103 \\
\hline Euterpe edulis & 15 & 18 & 1 & & & & & & 34 \\
\hline Erythrina falcata * & 3 & 2 & 5 & 6 & 3 & 3 & 5 & & 27 \\
\hline Schinus terebinthifolius & 22 & 4 & & & & & & & 26 \\
\hline Casearia sylvestris & 11 & 6 & 3 & & & & & & 20 \\
\hline Guarea kunthiana & 18 & & 1 & & & & & & 19 \\
\hline Morta & 5 & 5 & 2 & & & & & & 12 \\
\hline Cestrum coriaceum & 9 & & & & & & & & 9 \\
\hline Ficus trigona & 4 & 2 & & 2 & 1 & & & & 9 \\
\hline Cyathea delgadii ** & 8 & & & & & & & & 8 \\
\hline Endlicheria paniculata & 4 & 3 & & & & & & & 7 \\
\hline Rollinia laurifolia & 4 & 3 & & & & & & & 7 \\
\hline Ficus citrifolia & 4 & 2 & 1 & & & & & & 7 \\
\hline Sorocea bonplandii & 6 & & & & & & & & 6 \\
\hline Piper sp. & 6 & & & & & & & & 6 \\
\hline Cecropia glaziovi & 1 & 2 & 2 & & & & & & 5 \\
\hline Maclura tinctoria & 5 & & & & & & & & 5 \\
\hline Tibouchina granulosa & 3 & 1 & 1 & & & & & & 5 \\
\hline Protium warmingianum & 4 & & & & & & & & 4 \\
\hline Nectandra oppositifolia & 4 & & & & & & & & 4 \\
\hline Mollinedia floribunda & 4 & & & & & & & & 4 \\
\hline Sapium biglandulosum & 1 & 2 & 1 & & & & & & 4 \\
\hline Piper lhotzkyanum & 4 & & & & & & & & 4 \\
\hline Luehea grandiflora * & 2 & 1 & & & & & & & 3 \\
\hline Ficus luschnathiana & 1 & & 1 & & & & 1 & & 3 \\
\hline $\begin{array}{l}\text { Syagrus romanzoffiana } \\
\text { natian }\end{array}$ & & 2 & 1 & & & & & & 3 \\
\hline Ficus guaranitica & & & & & & 1 & 1 & 1 & 3 \\
\hline Piper aduncum & 2 & & & & & & & & 2 \\
\hline Trichilia lepidota & 2 & & & & & & & & 2 \\
\hline Alchornea iricurana & 1 & 1 & & & & & & & 2 \\
\hline Copaifera lansdorffii & 2 & & & & & & & & 2 \\
\hline Solanum cernuum & 2 & & & & & & & & 2 \\
\hline Alsophila sternbergii ** & 1 & 1 & & & & & & & 2 \\
\hline Xylopia sericea & & 1 & 1 & & & & & & 2 \\
\hline Alophyllus petiolatus & 2 & & & & & & & & 2 \\
\hline Myrcia eriopus & 1 & & & & & & & & 1 \\
\hline Vernonia rubriramea * & 1 & & & & & & & & 1 \\
\hline Trichilia emarginata & 1 & & & & & & & & 1 \\
\hline Matayba elaeagnoides & 1 & & & & & & & & 1 \\
\hline Randia armata & 1 & & & & & & & & 1 \\
\hline Myrcia fallax & 1 & & & & & & & & 1 \\
\hline Hyeronima alchorneoides & & & & 1 & & & & & 1 \\
\hline Plathymenia foliolosa * & & & & 1 & & & & & 1 \\
\hline Inga laurina & & & 1 & & & & & & 1 \\
\hline Trichilia pallida & 1 & & & & & & & & 1 \\
\hline Cabralea canjerana & 1 & & & & & & & & 1 \\
\hline Andira fraxinifolia & 1 & & & & & & & & 1 \\
\hline Machaerium nictitans * & & & 1 & & & & & & 1 \\
\hline Swartzia myrtifolia & 1 & & & & & & & & 1 \\
\hline Total & 246 & 72 & 23 & 16 & 7 & 5 & 7 & 1 & 377 \\
\hline
\end{tabular}

* Plantas anemocóricas e ** plantas com esporos dispersos pelo vento. 
Poucas sementes de Erythrina falcata teriam chegado ao local em questão por anemocoria, havendo, portanto, a hipótese de essa população ter baixa diversidade genética causada pelo efeito fundador. A confirmação dessa hipótese fortalece a tese de que Erythrina falcata iniciou o processo sucessional na mata alagada por meio da chuva de sementes pela anemocoria, o que teria restringido o número de diásporos que chegaram, estreitando a base genética e originando o efeito fundador. Caso a diversidade genética seja alta, é fortalecida a hipótese de a chuva de sementes ter sido por meio de endozoocoria, pois sementes teriam chegado diversas vezes, o que aumentou a possibilidade de possuírem diferentes constituições gênicas, ampliou a base genética e evitou o efeito fundador.

Pela capacidade de tolerar alagamento de suas raízes, de ser uma espécie heliófila (Krukoff, 1939; Lorenzi, 1992) e de se associar com bactérias nitrificantes, formando nódulos ativos (observação de campo), a população de Erythrina falcata apresenta as condições para ter iniciado a colonização nessa área de pastagem degradada e alagada do passado. Como consequiência, teria dado origem aos primeiros poleiros naturais para pouso de pássaros, aspecto este fundamental para o incremento da endozoocoria (Andrade-Melo, 1997), fortemente predominante em sua estrutura atual. Sua população foi considerada como a única adequada ao estudo genético que se propõe neste trabalho.

A associação de Erythrina falcata com espécies do gênero Ficus, notadamente Ficus guaranitica, pode ter determinado a essência da estrutura dessa floresta no início do processo sucessional, um sistema de baixa diversidade, e pode ter sido determinante de seu sucesso pela capacidade de o sistema radicular de espécies de Ficus do subgênero Urostigma fixar solos e até rochedos
(Carauta, 1989). Todas as espécies de Ficus representadas nessa floresta pertencem ao referido subgênero.

Scarano et al. (1997) e Scarano (2000) referem-se a florestas alagadas da zona costeira do Sudeste brasileiro como sistemas de baixa diversidade. Não é o caso da atual estrutura da mata alagada, mas esta pode ter sido um sistema de baixa diversidade em seu início, quando predominavam Erythrina falcata e espécies de Ficus e o ambiente era mais seletivo em suas condições de estabilidade de substrato e luz.

$\mathrm{Na}$ análise de como a anemocoria se comportou na chuva de sementes, fica evidente que quanto menor o diásporo maior o número de indivíduos estabelecidos por espécie florestal anemocórica, conforme a correlação por postos de Spearman - $r_{s}$ - (Quadro 3). As espécies Erythrina falcata e Vernonia rubriramea não foram consideradas na análise, pelo fato de a primeira ser endozoocórica eventual e a segunda não ser florestal. Vernonia rubriramea teve apenas um indivíduo amostrado, porque os indivíduos dessa espécie dificilmente atingem tamanhos para serem amostrados pelo critério de inclusão utilizado. É uma espécie muito comum em pastagens, conhecida popularmente como assa-peixe. Erythrina falcata ocorreu com um número de indivíduos muito superior ao das outras espécies anemocóricas, número maior até que a soma de todos os indivíduos dessas espécies.

\subsection{Isoenzimas}

Nas inferências sobre a estrutura genética da população de Erythrina falcata, foram utilizados oito sistemas enzimáticos. Destes, apenas quatro apresentaram padrão de bandeamento consistente (Figura 2). Um total de seis loci foi observado.

Quadro 3 - Correlação por postos de Spearman $\left(r_{s}\right)$ entre o maior tamanho de diásporos e o menor número de indivíduos das espécies florestais anemocóricas exclusivas na mata alagada

Table 3 - Spearman correlation between the greatest size of propagules and the smallest number of individuals of exclusive anemochoric forest species in flooded forest

\begin{tabular}{|c|c|c|c|c|}
\hline Espécie & $\begin{array}{l}\text { Maior Tamanho de } \\
\text { Diásporos }\end{array}$ & $\begin{array}{l}\text { Menor Número de } \\
\text { Indivíduos }\end{array}$ & di & $\mathrm{di}^{2}$ \\
\hline Plathymenia foliolosa & 1,0 & 1,5 & 0,5 & 0,25 \\
\hline Machaerium nictitans & 2,0 & 1,5 & 0,5 & 0,25 \\
\hline Luehea grandiflora & 3,0 & 4,0 & 1,0 & 1,00 \\
\hline Tibouchina granulosa & 4,0 & 5,0 & 1,0 & 1,00 \\
\hline Alsophila sternbergii & 5,5 & 3,0 & 2,5 & 6,25 \\
\hline Cyathea delgadii & 5,5 & 6,0 & 0,5 & 0,25 \\
\hline
\end{tabular}

$\Sigma \mathrm{di}^{2}=0,9 ; r_{s}=0,958>$ que valor crítico para $\mathrm{n}=6(0,943)$, correlação significativa a $1 \%$. 

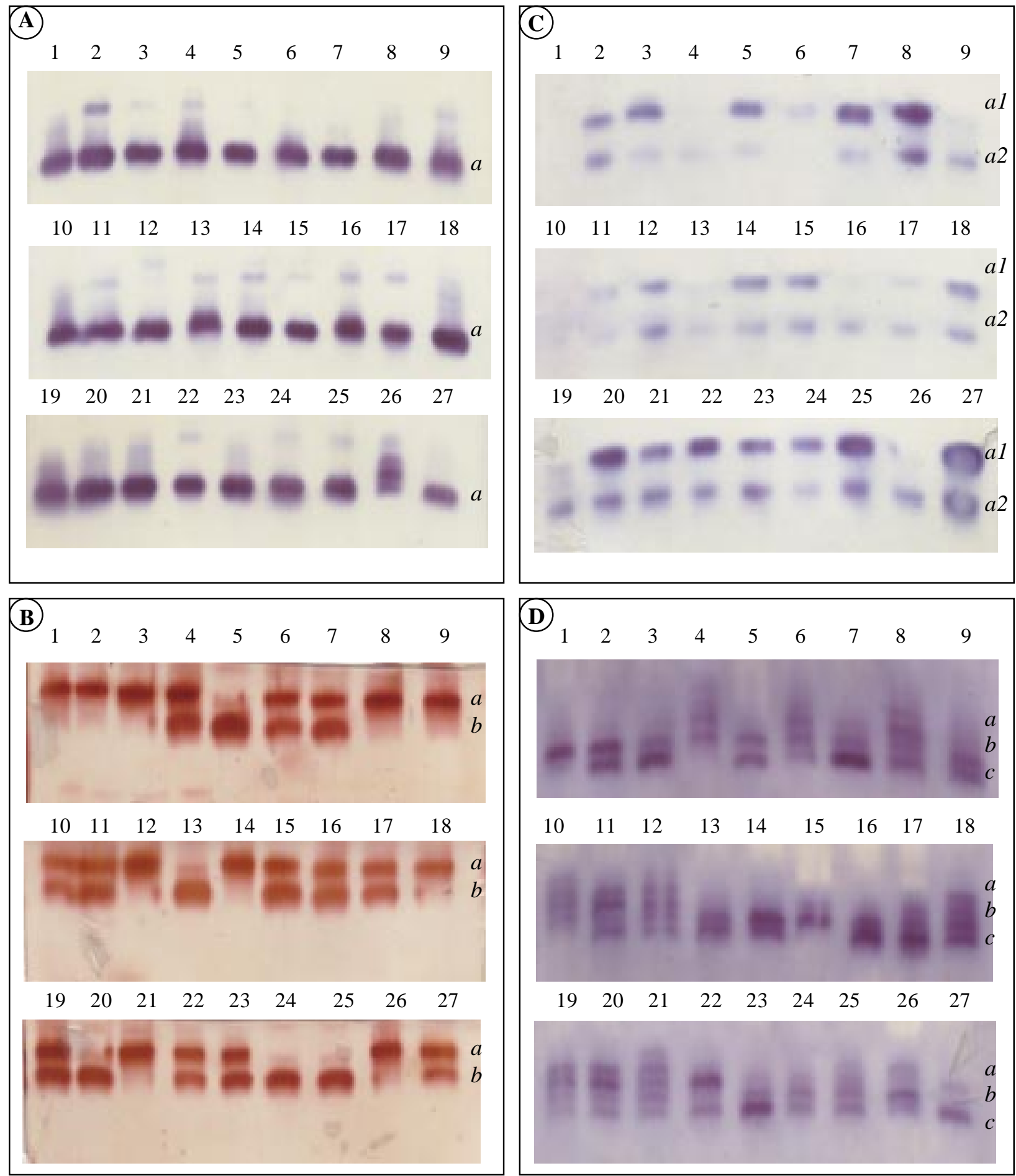

Figura 2 - Géis das enzimas isocitrato desidrogenase (A), peroxidase (B), fosfogluco mutase 1 e 2 (C) e xiquimato desidrogenase (D), em tecidos foliares de Erythrina falcata.

Figure 2 - Geis of isocitrate dehydrogenase (A), peroxidase (B), phosphoglyco mutase 1 and 2 (C) and xiquimate dehydrogenase (D) enzymes in foliar tissues of Erythrina falcata. 


\subsubsection{Sistemas Isoenzimáticos Analisados}

\subsubsection{Isocitrato Desidrogenase (IDH - E.C. 1.1.1.42)}

Embora seja uma enzima dimérica, apenas um indivíduo de Erythrina falcata apresentou-se com a forma dimérica, sendo os outros 26 portadores de um único alelo. Assim, o loco foi considerado monomórfico (Figura 2).

\subsubsection{Peroxidase (PRX - E.C. 1.1.1.7)}

Dois loci para peroxidase foram detectados nesta população, porém apenas um deles é mostrado no zimograma (Figura 2B), situado na região catódica.

\subsubsection{Fosfogluco Mutase (PGM - E.C. 1.1.1.49)}

Esta enzima apresenta dois loci e é monomérica (Weeden \& Wendel, 1989; Gotlieb 1982). Neste trabalho ela se comportou como tal, apresentando duas zonas de atividade com uma única forma alélica na maioria dos indivíduos, exceto os indivíduos 1 e 10, que apresentaram alelos nulos (Figura 2C).

\subsubsection{Xiquimato Desidrogenase (SKD - E.C. 1.1.1.25)}

O zimograma de Skd apresentou três formas alélicas, portanto é um loco polimórfico em que a maioria dos indivíduos apresentou as formas a e b, fenótipos heterozigotos (Figura 2D).

\subsubsection{Variabilidade Genética e Sistema de Cruzamento na População de Erythrina falcata}

Os loci Idh, Pgm1, Pgm2 Prx1 e Skd foram analisados com relação às freqüências alélicas (Quadro 4). Idh, Pgm1 e Pgm2 apresentaram apenas uma forma alélica, enquanto Prx e Skd apresentaram duas e três formas, respectivamente (Figura $2 \mathrm{~b}$ e d).

A variação genética da população foi quantificada pela porcentagem de locos polimórficos, número médio de alelos por loco e heterozigosidade total (Quadro 4)

É importante ressaltar que as estimativas de locos polimórficos $(33,33 \%)$ e o número médio de alelos $(1,5)$ dependem do número de plantas, do número e dos tipos de enzimas e do critério de polimorfismo adotado (Brown $\&$ Weir, 1983). Segundo Acquach (1992), 100 indivíduos constituem uma amostra representativa. No entanto, 27 plantas representam a totalidade dessa população.

A heterozigosidade total observada na população de Erythrina falcata foi de 0,204, que é considerada alta, e está relacionada com a diversidade genética e o número das sementes que chegaram ao local pela chuva de diásporos (Quadro 4).

Nos loci polimórficos, a heterozigose média por loco próxima de 0,5 provavelmente está relacionada com a distribuição uniforme das frequiências alélicas nesta população, uma vez que os heterozigotos são mais freqüentes quando aquelas intermediárias (Falconer, 1987).

Em plantas alógamas no equilíbrio de HardyWeinberg, a heterozigosidade observada equivale à

Quadro 4 - Freqüências alélicas dos loci $I d h, \operatorname{Pgm}_{1}, \operatorname{Pgm}_{2}, P r x_{1}, P r x_{2}$ e $S k d$, em plantas de $E$. falcata Table 4 - Allelic frequence of Idh, Pgm $1, \operatorname{Pgm}_{2}$, Prx $x_{1}, \operatorname{Prx}_{2}$ and Skd loci in Erythrina falcata plants

\begin{tabular}{|c|c|c|c|c|c|c|c|}
\hline Loci & Alelos & Frequiência & $\begin{array}{l}\text { Heterozigos por } \\
\text { Loco }\end{array}$ & $\begin{array}{c}\% \text { Loci } \\
\text { Polimórficos }\end{array}$ & $\begin{array}{l}\text { Número Médio de } \\
\text { Alelos/Loco }\end{array}$ & $\begin{array}{l}\text { Número de } \\
\text { Alelos/Loco } \\
\text { Polimórfico }\end{array}$ & $\begin{array}{c}\text { Heterozigose } \\
\text { Média } \\
\text { Observada }\end{array}$ \\
\hline$I d h$ & $\mathrm{a}$ & 1,00 & 0,0 & 0,0 & 1,0 & 0,0 & 0,0 \\
\hline $\mathrm{Pgm}_{1}$ & a & 1,00 & 0,0 & 0,0 & 1,0 & 0,0 & 0,0 \\
\hline $\mathrm{Pgm}_{2}$ & a & 1,00 & 0,0 & 0,0 & 1,0 & 0,0 & 0,0 \\
\hline $\operatorname{Prx}_{1}$ & $\begin{array}{l}a \\
b\end{array}$ & $\begin{array}{l}0,593 \\
0,407\end{array}$ & 0,444 & 0,167 & 2,0 & 2,00 & 0,074 \\
\hline$P r x_{2}$ & $\mathrm{a}$ & 1,00 & 0,0 & 0,0 & 1,0 & 0,0 & 0,0 \\
\hline Skd & $\begin{array}{l}\mathrm{a} \\
\mathrm{b} \\
\mathrm{c}\end{array}$ & $\begin{array}{l}0,185 \\
0,407 \\
0,407\end{array}$ & 0,778 & 0,130 & 3,0 & 3,0 & 0,130 \\
\hline$N^{*}$ & 27 & - & - & 33,33 & 1,5 & 2,5 & 0,204 \\
\hline
\end{tabular}

* número de indivíduos. 
freqüência esperada de heterozigotos, o que foi verificado pelo teste $\chi^{2}$. O desvio não foi verificado pelo teste $\chi^{2}$ para os dois loci, Prx e $S k d$ (Quadro 5). Os demais loci não foram considerados neste estudo, pelo fato de serem todos homozigotos, ou seja, apresentarem alelos fixos.

O índice de fixação de Wright ou coeficiente de endogamia nos loci ( $\hat{I}$ ) foi calculado, fornecendo estimativa do desvio em relação ao esperado no equilíbrio de Hardy-Weinberg (Quadro 6). O valor de I varia de -1 na heterose completa, 0 no equilíbrio de Hardy-Weinberg e +1 na fixação alélica completa. Os índices obtidos nos loci Prx e $S k d$ são baixos, próximos de zero, o que confirma para estes loci que a população encontra-se no equilíbrio de Hardy-Weinberg.

\subsubsection{Sistema de Cruzamento}

A análise de variâncias das frequiências alélicas além da estimativa da taxa de fertilização cruzada $(t)$ permitiu também a obtenção das estimativas do coeficiente de endogamia na espécie analisada $(F)$. No Quadro 7, observa-se a diferença entre os dois coeficientes de endogamia nas estimativas por loco. A taxa de cruzamento na espécie $(0,6186)$ permite classificar E. falcata como espécie de fecundação cruzada predominante. Houve variação da estimativa de $t$ em ambos os loci. Estas taxas de cruzamento fornecem uma idéia da predominância da fecundação cruzada ou da autofecundação, porém nem sempre devem ser tratadas como constantes, porque ocorre variação considerável nas populações da maioria das espécies estudadas (Hamrick, 1982). Embora estes estimadores forneçam uma idéia da estrutura genética da espécie, eles são tendenciosos. Entretanto, as expressões dessas tendências são função de $1 / \mathrm{n}$, o que indica que elas se tornam desprezíveis com o aumento do tamanho da amostra (n) (Muniz et al., 1996). A estimativa de $\mathrm{t}=0,618$ provavelmente contribuiu para que essa população entrasse em equilíbrio de Hardy-Weinberg, como já demonstrado.

Quadro 5 - Teste de $\chi^{2}$ para desequilíbrio de Hardy-Weinberg nos loci Prx e Skd na população de Erythrina falcata

Table 5 - $\chi^{2}$ test for Hardy-Weinberg balance in Prx and Skd loci in Erythrina falcata population

\begin{tabular}{|c|c|c|c|c|c|}
\hline Loci & Classes & $\begin{array}{l}\text { Freqüência } \\
\text { Observada }\end{array}$ & $\begin{array}{c}\text { Freqüência } \\
\text { Esperada }\end{array}$ & $\chi^{2}$ & $\begin{array}{l}\text { Graus de } \\
\text { Liberdade }\end{array}$ \\
\hline $\operatorname{Prx}$ & $\begin{array}{c}\boldsymbol{A A} \\
\text { Aa } \\
\text { aa }\end{array}$ & $\begin{array}{r}10,00 \\
12,00 \\
5,00\end{array}$ & $\begin{array}{r}9,48 \\
13,04 \\
4,48\end{array}$ & $0,1711^{\mathrm{ns}}$ & 1 \\
\hline Skd & $\begin{array}{l}a \boldsymbol{a} \\
\mathrm{ab} \\
\mathrm{ac} \\
\mathrm{bb} \\
\mathrm{bc} \\
\mathrm{cc}\end{array}$ & $\begin{array}{r}0,00 \\
5,00 \\
5,00 \\
\\
3,00 \\
11,00 \\
3,00\end{array}$ & $\begin{array}{l}0,926 \\
4,073 \\
4,073 \\
\\
4,481 \\
8,962 \\
4,481\end{array}$ & $2,790^{\mathrm{ns}}$ & 3 \\
\hline
\end{tabular}

${ }^{\text {ns }}$ não-significativo a $\mathrm{P}<0,05$. Teste de $\chi^{2}$. Os demais loci analisados nesta população apresenta fixação alélica, portanto com $\hat{I}=1$.

Quadro 6 - Estimativas dos índices de fixação $(\hat{I})$ nos loci $\operatorname{Prx}$ e Skd, na população de Erythrina falcata. (He) heterozigoto esperado, (Ho) heterozigoto observado

Table 6 - Fixation index estimation (I) in Prx and Skd loci in Erythrina falcata population. (He) expected heterozigote, (Ho), observed heterozigote

\begin{tabular}{|c|c|c|c|}
\hline Loci & Ho & He & $\hat{I}$ \\
\hline Prx & 0,4440 & 0,482 & 0,07883 \\
\hline Skd & 0,5185 & 0,493 & $-0,02550$ \\
\hline
\end{tabular}

Quadro 7 - Estimativas dos coeficientes de endogamia $(F)$ e taxa de fertilização $(t)$ das plantas da população de Erythrina falcata

Table 7 - Endogamy estimation (F) and cross fertilization (t) of Erythrina falcata population plants

\begin{tabular}{|c|c|c|}
\hline Loci & Estimativa de $\mathrm{F}$ & Estimativa de $\mathrm{t}$ \\
\hline Prx & 0,183 & 0,690 \\
\hline Skd & 0,292 & 0,547 \\
\hline Média & 0,237 & 0,618 \\
\hline
\end{tabular}

R. Árvore, Viçosa-MG, v.27, n.4, p.561-574, 2003 
Pelos resultados de alta heterozigozidade e do equilíbrio de Hardy-Weinberg para os loci Prx e Skd, fica evidente que houve a chegada de diásporos suficientes para conferir variabilidade genética capaz de estabelecer uma população estável. Assim, fica reforçada a hipótese de chegada de sementes de Erythrina falcata mais efetivamente por endozoocoria que por anemocoria. Se a chuva de sementes se efetivasse por anemocoria, a chegada de sementes seria episódica, como ocorreu com as outras populações anemocóricas, que possuem baixa densidade na comunidade. Então, os vários indivíduos da população de Erythrina falcata teriam baixa heterozigosidade originada do endocruzamento resultante da estreita base genética conferida pelas poucas sementes fundadoras.

\section{CONCLUSÕES}

Considerando o exposto no presente trabalho, conclui-se que: 1- a população de Erythrina falcata possuía condições biológicas e ecológicas para iniciar a sucessão secundária nas condições que, supõe-se, havia no local do início desse processo; 2- a população de Erythrina falcata estava presente no início do processo sucessional da mata alagada, conforme mostra sua distribuição de freqüências em classes de diâmetros do caule; 3- a colonização se iniciou com diversidade genética relativamente alta no conjunto de plantas de Erythrina falcata oriundo de chegada de sementes por endozoocoria mais efetiva que por anemocoria; 4- a alta diversidade genética da população de Erythrina falcata pode ter sido um dos fatores determinantes do sucesso de colonização da área ocupada pela mata alagada; 5- a associação de Erythrina falcata com figueiras, notadamente Ficus guaranitica, pode ter sido determinante no sucesso desse processo em seu início, por suas raízes tolerarem o alagamento, por serem heliófilas, por Erythrina falcata ser capaz de fixar nitrogênio atmosférico, pela estrutura de tamanhos dessas populações mostrar que possivelmente são as mais antigas do fragmento, e pela capacidade de o sistema radicular dessas figueiras fixarem o solo; e 6- essa associação inicial deve ter funcionado como sistema de baixa diversidade de espécies, comparável a outras florestas alagadas do Sudeste brasileiro.

\section{REFERÊNCIAS BIBLIOGRÁFICAS}

ACQUACH, G. Practical protein electrophoresis for genetic research. Portland: Discorides Press, 1992. 131 p.

R. Árvore, Viçosa-MG, v.27, n.4, p.561-574, 2003
ALFENAS, A. C. et al. Eletroforese de proteínas e isoenzimas de fungos e essências florestais. Viçosa: UFV, 1991. $242 \mathrm{p}$.

ALFENAS, A. C.; BRUNE, W. Eletroforese em gel de amido. In: ALFENAS, A C. (Ed.). Eletroforese de isoenzimas e proteínas afins: fundamentos e aplicações em plantas e microrganismos. Viçosa: UFV, 1998. p. 115-148.

ANDRADE MELO, V. Poleiros artificiais e dispersão de sementes por aves em uma área de reflorestamento no Estado de Minas Gerais. 1997. 40 f. Dissertação (Mestrado em Ciência Florestal) - Universidade Federal de Viçosa, Viçosa, 1997. $40 \mathrm{p}$.

BROWN, A. H. D.; WEIR, B. S. Measuring genetic variability in plant populations. In: TANKESLEY, S. D., ORTON, T. J. (Eds.). Isozymes in plant genetics and breeding: Part A. Amsterdan: Elsevier; 1983. p. 219-239.

CARAUTA, J. P. Ficus (Moraceae) no Brasil: conservação e taxonomia. Albertoa, v. 2, n. 1, p. 1-365. 1989.

COMISSÃO GEOGRÁFICA E GEOLÓGICA DE MINAS GERAIS - CGGMG. Viçosa. Folha n ${ }^{\circ} 25$ N1E3. Belo Horizonte, 1930. 1 mapa.

CORREA, G. F. Modelo de evolução e mineralogia da fração argila de solos do Planalto de Viçosa, MG. 1983. 87 f. Dissertação (Mestrado em Solos e Nutrição de Plantas) - Universidade Federal de Viçosa, Viçosa, 1983.

COTA, A. P. Manejo de fragmentos florestais para conservação da biodiversidade. 1998. 67 f. Monografia. Universidade Federal de Viçosa, Viçosa, 1998.

DEPARTAMENTO NACIONAL DE METEOROLOGIA DNM. Normais climatológicas (1961 - 1990). Brasília: 1992. $84 \mathrm{p}$.

EMPRESA BRASILEIRA DE PESQUISA AGROPECUÁRIA - EMBRAPA. Sistema brasileiro de classificação dos solos. Brasília: 1999. 412 p.

FALCONER, D. S. Introdução à genética quantitativa. Viçosa: Universidade Federal de Viçosa, 1987. 279 p.

GENTRY, A. H. Dispersal ecology and diversity in neotropical forest communities. Sonderb. Naturwiss Ver., v. 7, p. 303-314, 1983.

GOLFARI, L. Zoneamento ecológico do Estado de Minas Gerais. Belo Horizonte: Centro de Pesquisa Florestal da Região do Cerrado. 1975. 65 p. 
GOTTLIEB, L. D. Conservation and duplication of isozymes in plants. Science, v. 216, p. 373-380, 1982.

HAMRICK, J. L. Plant populations genetics and evolution. American Journal of Botany, v. 69, p. 1685-1693, 1982.

HARPER, J. L. Population biology of plants. London: Academic Press, 1977. 892 p.

KAGEYAMA, P. Y. Estudo para implantação de matas de galeria na bacia hidrográfica do Passa-Cinco visando utilização para abastecimento público. Piracicaba:

Universidade de São Paulo, 1986. 236 p.

KRUKOFF, A. The American species of Erythrina. Brittonia, v. 3, n. 2, p. 205-337. 1939.

LORENZI, H. Árvores brasileiras: Manual de identificação e cultivo de plantas arbóreas nativas do Brasil. Nova Odessa: Plantarum, 1992. $532 \mathrm{p}$.

MARISCAL-FLORES, E. J. Potencial produtivo e alternativas de manejo sustentável de um fragmento de mata atlântica secundária, Município de Viçosa, Minas Gerais. 1993165 f. Dissertação (Mestrado em Ciência Florestal) - Universidade Federal de Viçosa, Viçosa, 1993.

MARTINS, F. R. Estrutura de uma floresta mesófila. Campinas: UNICAMP, 1991. 246 p.

MATHES, L. A. F. Composição florística e fenologia de uma floresta residual do planalto paulista: Bosque dos Jequitibás, Campinas, SP. 1980. 225 f. Dissertação (Mestrado em Ciências Biológicas) - Universidade Estadual de Campinas, Campinas, 1980.

MEIRA-NETO, J. A. A. et al. Estrutura de uma floresta estacional semidecidual aluvial em área diretamente afetada pela usina hidrelétrica de Pilar, Ponte Nova, Zona da Mata de Minas Gerais. Revista Árvore, v. 21, n. 2, p. 213-219, 1997.

MEIRA-NETO, J. A. A. et al. Estrutura de uma floresta estacional semidecidual insular em área diretamente afetada pela usina hidrelétrica de Pilar, Guaraciaba, Zona da Mata de Minas Gerais. Revista Árvore, v. 22, n. 2, p. 179-184, 1998.

MEYER, H. A. Structure, growth, and drain in balanced uneven-aged forests. Journal of Forestry, v. 50, p. 85-92, 1952.

MORELlATO, L. P. C.; LEITÃO-FILHO, H. F. Padrões de frutificação e dispersão na Serra do Japi. In: História Natural da Serra do japi: Ecologia e preservação de uma área florestal no Sudeste do Brasil. Campinas: UNICAMP/ FAPESP, 1992. $321 \mathrm{p}$.
MOTA, L. P. Diamfito. Programa de análise de distribuição diamétrica. Viçosa: Universidade Federal de Viçosa, 1995.

MUELLER-DOMBOIS, D.; ELLENBERG, H. Aims and methods of vegetation ecology. New York: John Wiley \& Sons, 1974. 547 p.

MUNIZ, J. A.; BANBIN, D.; VENCOVSKY, R. Properties of estimators of the inbreeding coefficient and the rate of cross fertilization obtained from gene frequency data in a diploid population. Brazilian Journal of Genetics, v. 19, n. 3, p. 485-491, 1996.

OLIVEIRA-FILHO, A. T. et al. Comparison of the woody flora and soils of six areas of montane semideciduous forest in southern Minas Gerais, Brazil. Journal of Botany, v. 51, n. 3, p. 355-389, 1994a.

OLIVEIRA-FILHO, A. T. et al. Effect of soils and topography on the distribution of tree species in a tropical riverine forest in Southeastern Brazil. Journal Tropical Ecology, v. 10, p. 483-508, 1994b.

ORTIZ-PULLIDO, R.; LABORDE, J.; GUEVARA, S. Frugivoría por aves en un paisaje fragmentado: consequencias en la dispersión de semillas. Biotropica, v. 32, n. 3, p. 473-488, 1999.

REZENDE, S. B. Estudo de crono-toposeqüência em Viçosa - Minas Gerais. 1971. 71 f. Dissertação (Mestrado em Solos e Nutrição de Plantas) - Universidade Federal de Viçosa, Viçosa, 1971.

SCARANO, F. R. et al. Plant establishment on flooded and unflooded patches of freshwater swamp forest of southeastern Brazil. Journal of Tropical Ecology, n. 14, p. 793-903, 1997.

SCARANO, F. R. Marginal plants: functional ecology at the Atlantic Forest periphery. In: TÓPICOS atuais em Botânica. Brasília: Sociedade Botânica do Brasil, Embrapa, 2000. 398 p.

SCHIAVINI, I. Estrutura das comunidades arbóreas de mata de galeria da Estação Ecológica do Panga (Uberlândia - MG). 1992. 132 f. Tese (Doutorado em Ciências Biológicas) - UNICAMP, Campinas, 1992. 132 p.

SEVILHA, A. C. Composição e estrutura da Mata de Galeria do Capetinga, na Fazenda Água Limpa, Brasília, DF, dez anos após um incêndio acidental. 1999. $122 \mathrm{f}$. Dissertação (Mestrado em Botânica) - Universidade de Brasília, Brasília, 1999.

R. Árvore, Viçosa-MG, v.27, n.4, p.561-574, 2003 
SILVA-JÚNIOR, M. C. FURLEY, P. A.; RATTER, J. A. Variations in tree communities and soils with slope in gallery Forest, Federal District, Brazil. In: ANDERSON, M. G.; BROOKS, S. M. (Eds.) Advances in hillslope processes. London: John Wiley \& Sons, 1996. p. 451-469.

SHAW, C. R.; PRASSAD, R. Starch gel electrophoresis of enzymes - a compilation of recipes. Biochemistry

Genetics, v. 4, p. 297-320, 1970.

SHEPHERD, G. J. Fitopac 1. Manual do usuário. Departamento de Botânica - Campinas: UNICAMP, 1994.

SOLTIS, D. E. et al. Starch gel electrophoresis of ferns: a compilation of grind buffers, gel and eletrode buffers, gel and eletrode buffers, and staining schedules. American Fern. Journal, v. 73, p. 9-27, 1983.
SPIEGEL, M. R. Estatística. São Paulo: McGraw-Hill do Brasil, 1974. $580 \mathrm{p}$.

VALVERDE, O. Estudo regional da Zona da Mata de Minas Gerais. Revista Brasileira de Geografia, v. 20, n. 1, p. 1-82, 1958.

VELOSO, H. P.; RANGEL FILHO, A. L. R.; LIMA, J. C. A. Classificação da vegetação brasileira, adaptada a um sistema universal. Rio de Janeiro: Fundação Instituto Brasileiro de Geografia e Estatística, IBGE, 1991. 123 p.

WEEDEN, N. F.; WENDEL, J. F. Genetics of plant isozymes. In: SOLTIS, D.E. Isozymes in plant biology (Soltis, D. E. \& Soltis, eds.). Discorides Press, Portland: 1989. p. 46-72. 